\title{
Amount of PPE against COVID-19 to Sub-Saharan Africa may determine the region's uptake to patient care and clinical research
}

\author{
Thomas Nyirenda ${ }^{1 *}$, Min Jae Shin ${ }^{2}$, Sue Min Shin ${ }^{3}$ and David S Chung ${ }^{4}$ \\ ${ }^{1}$ European and Developing Countries Clinical Trials Partnership, Medical Research Council, Francie van Zyl Drive, South Africa \\ ${ }^{2}$ School of Arts \& Sciences, Johns Hopkins University, Baltimore, MD, USA \\ ${ }^{3}$ College of Arts \& Sciences, Emory University, Atlanta, GA, USA \\ ${ }^{4}$ School of Medicine, University of Virginia, Charlottesville, VA 22904, USA
}

\begin{abstract}
Sub-Saharan Africa is faced with weak health systems and disproportionately inadequate number of health workers. Some studies have shown high vulnerability of these workers to occupational health infections from their patients. The COVID-19 pandemic which is spreading to the region and has affected the health work force in the west is likely to do the same in Sub-Saharan Africa. Non-availability or inadequate supply of good personal protective equipment (PPE) may become a disincentive to caring for the diagnosed cases and slow uptake for clinical research in the region. Slow manufacturing plans, poor supply chain and poor adherence by health workers could all contribute to the scarcity and effectiveness of PPE to the region if not well managed. Ensuring PPE are adequately available may be a big challenge for many of the poor countries in sub-Saharan Africa, but it is huddle that needs to be avoided for better uptake of clinical care and research.
\end{abstract}

\begin{abstract}
Abbreviations: CDC: Centres for Disease Control; COVID-19: Corona virus disease 2019; PPE: Personal Protective Equipment; USA: United States of America; WHO: World Health Organisation

Since the World Health Organisation (WHO) declared COVID-19 a pandemic on 11 March 2020, there has been an increase of its morbidity and mortality in over 180 countries in the world [1]. In Africa cases have been rising too with countries with both bigger and smaller economies recording new cases every day. Such increases of confirmed cases in Sub-Saharan Africa pose a worrying trend to the region's health care and research capacity that is constantly faced with weak health systems punctuated by low wages, lack of supplies and equipment and with inadequate numbers of skilled health workers.
\end{abstract}

Successful disease control in sub-Saharan Africa requires careful planning with engagement with local communities and the underresourced health services whose annual budgets will normally not include large stocks of personal protective equipment (PPE). Such planning requires adequate time too. Studies of nosocomial infections show vulnerability of African health workers to common diseases. For example, it is known that TB health workers in sub-Saharan Africa are at highest risk of succumbing to the infection and its disease partly attributed to lack of PPE in health facilities, calling for urgent interventions to ensure the safety of the front-line workers $[2,3]$. During the COVID-19 pandemic wide use of PPE should cover all departments of the health care services as this recent pandemic has shown. In every hospital or clinic, away from a respiratory diseases' clinic, lies other sections worth covering with PPE such as the obstetrics ward where the second stage of labour exposes providers to aerosol and increases the risk of COVID-19 if the mother being treated is infected with COVID-19 [4]. Non-availability or inadequate supply of good personal protective equipment (PPE) may become a disincentive to caring for the diagnosed cases and slow uptake for clinical research in the African region. Urgent need for PPE for health workers in subSaharan Africa will likely not come with lesser challenges. During the current COVID-19 pandemic even countries with prior experience of stocking and distributing PPE during the Ebola epidemic, have faced shortages, widely varying demand, use, and supply strategies, with hospitals requiring larger amounts as the pandemic progresses [5]. Similar manufacturing and supply chain mechanism may be the first challenge sub-Saharan Africa will face. Repurposing PPE supply and its supply chain like what the USA CDC quickly recommended [6] is only possible when the supply is readily available and accessible. Many weaker African countries depend on donations and if these do not reach its affected areas on time, the second challenge for sub-Saharan Africa, in the face of the pandemic will be how to quickly kickstart its own manufacturing and distributing supplies of PPE for their local health care systems. For some materials such as face masks proof of concept, prototypes and their three-dimensionally (3D) printing technologies are available [7]. However, adoption of such technologies requires training and capacity building of the local manufacturing sectors. In addition, availability of PPE does not guarantee immediate safety. It is reported that during the 2014-2016 Ebola virus epidemic

${ }^{\star}$ Correspondence to: Thomas Nyirenda, MD MPH, European and Developing Countries Clinical Trials Partnership, Medical Research Council, Francie van Zyl Drive, Cape Town 7505, South Africa, Tel: 0027824174743; E-mail: nyirenda@edctp.org

Key words: COVID-19, Clinical Care, Research, Sub-Saharan Africa

Received: May 04, 2020; Accepted: May 22, 2020; Published: May 27, 2020 
in Africa, more 500 health care workers died in spite of the use PPE [8]. Permissible range of motion, time to doff, comfort, and perceived risk are all important to get proper usage of PPE. In the outbreak of COVID-19 in Wuhan (China) a high prevalence of cutaneous irritation associated with N95 mask and goggle use was reported [9]. Ensuring adherence to available PPE is the third challenge sub-Saharan Africa health workers will face. The required long term use of PPE will depend on its feasibility and acceptability.

In conclusion, ensuring PPE are adequately available and properly used may be a big challenge for many of the poor countries in subSaharan Africa during the COVID-19 pandemic, but the expected huddles need to be properly managed to avoid reduced uptake of required clinical care and research during the pandemic in the region.

\section{Authorship and contribution}

Both TN and DC contributed to the structuring and editing the paper; while MS and SS contributed their ideas the first author through online consultation.

\section{Acknowledgement}

Not applicable.

\section{Funding}

Not applicable.

\section{Conflict of Interest}

None.

\section{References}

1. https://gisanddata.maps.arcgis.com/apps/opsdashboard/index.html\#/bda7594740fd$40299423467 \mathrm{~b} 48 \mathrm{e} 9 \mathrm{ecf} 6$

2. von Delft A, Dramowski A, Khosa C, Kotze K, Lederer P, et al. (2015) Why healthcare workers are sick of TB. Int J Infect Dis 32: 147-51. [Crossref]

3. Harries AD, Nyirenda TE, Banerjee A, Boeree MJ, Salaniponi FM (1999) Tuberculosis in health care workers in Malawi. Trans R Soc Trop Med Hyg 93: 32-35. [Crossref]

4. Palatnik A, McIntosh JJ (2020) Protecting Labor and Delivery Personnel from COVID-19 during the Second Stage of Labor. Am J Perinatol [Crossref]

5. Kamerow D (2020) Covid-19: the crisis of personal protective equipment in the US BMJ 2020: 369 .

6. Livingston E, Desai A, Berkwits M (2020) Sourcing Personal Protective Equipment During the COVID-19 Pandemic. JAMA 323: 1912-1914. [Crossref]

7. Swennen GRJ, Pottel L, Haers PE (2020) Custom-made 3D-printed face masks in case of pandemic crisis situations with a lack of commercially available FFP2/3 masks. Int J Oral Maxillofac Surg 49: 673-677. [Crossref]

8. Garibaldi BT, Ruparelia C, Shaw-Saliba K, Sauer LM, Maragakis LL, et al. (2019) A novel personal protective equipment coverall was rated higher than standard Ebola virus personal protective equipment in terms of comfort, mobility and perception of safety when tested by health care workers in Liberia and in a United States biocontainment unit. Am J Infect Control 47: 298-304. [Crossref]

9. Kantor J (2020) Behavioral considerations and impact on personal protective equipment (PPE) use: Early lessons from the coronavirus (COVID-19) outbreak. $J$ Am Acad Dermatol 82: 1087-1088. [Crossref]

Copyright: (C2020 Nyirenda T. This is an open-access article distributed under the terms of the Creative Commons Attribution License, which permits unrestricted use, distribution, and reproduction in any medium, provided the original author and source are credited. 